\title{
Cyber-Attacks and Freedom of Expression: Coercion, Intimidation and Virtual Occupation
}

\author{
Joe Burton \\ Université libre de Bruxelles \\ Avenue Franklin D. Roosevelt 50, CP 172/01 \\ Brussels 1050, Belgium \\ E-mail: jburton@waikato.ac.nz
}

Abstract: This article explores how cyber-attacks affect freedom of expression. It begins by outlining the literature on cyber coercion and exploring other conceptions of how offensive cyber operations have been used to shape adversary behaviour, including efforts to intimidate through cyberspace, and the concept of 'cyber swaggering'. The article moves on to explore how cyber-attacks have been used to undermine electoral process, to erode free and fair media reporting, and how manipulation of social media can constitute a 'virtual infiltration' and 'virtual occupation' of the information domain. The article then explores how cyber-attacks conducted during the conflict in Ukraine have limited or otherwise affected freedom of expression. I argue that the wider effects of cyber operations on political, civil and human rights have been underexplored in the cyber security literature; that cyber-attacks have adversely affected freedom of expression in the conflict in Ukraine and in other political disputes; and that the coercion concept is ill-suited to accounting for the sociopsychological impact of modern cyber operations.

Keywords: cyber coercion, freedom of expression, intimidation, Ukraine, virtual occupation 


\section{Introduction}

In recent years Ukraine has been subjected to a barrage of cyber-attacks targeting its electoral processes, power grids, media and public institutions. The country has been one of the biggest victims of offensive cyber operations in the post-Cold War era (Geers, 2015; Kostyuk \& Zhukov, 2019). Perhaps the most notable trend in the recent cyber literature on Ukraine has been to link patterns of offensive cyber activity to the practice of cyber coercion (Hodgson, 2018, p. 80; Valeriano, Jensen, \& Maness, 2018, p. 110). This literature explores how Russia has used cyber operations to influence political decisions by the government in Kyiv and to advance Russian interests in the ongoing conflict. This article contributes to analyses of the effects and results of attempted cyber coercion by exploring how and in what circumstances cyber-attacks can stifle and limit freedom of expression. In particular, it explores the impact of cyberattacks on freedom of expression occurring within the context of prolonged political and military disputes.

The article builds three core arguments. First, according to the traditional parameters of coercion - the use of military, kinetic, or physical force to influence an adversary's behaviour - the idea of cyber coercion is an ill fit. Cyber-attacks are never a use of force in themselves and the contingent elements of successful coercion - clear communication, credibility and reassurance - are often difficult to achieve. A more accurate conception of the effects of cyber-attacks is that cyber operations are a form of intentional bullying and intimidation that affect how individuals, groups and states act, including the things they do and the things they do not do. This includes the ability to express themselves free of fear of persecution or retribution. Second, if cyber-attacks are targeted at electoral systems, with the aim to corrupt, disrupt or alter perceptions among a population, then that constitutes a clear abrogation of freedom of expression. This has been a common feature of the cyber operations targeting Ukraine and has been brought to the forefront of cyber debates because of Russian subversion of US electoral processes in 2016. Third, cyber-attacks can affect freedom of expression through the 'virtual infiltration' and 'virtual occupation' of the information sphere. This involves the spread of disinformation in place of the accurate information that would allow citizens to form their political opinion without malicious interference. This last form of interference does not necessarily impact people's ability to express themselves directly, but to do so on the basis of uncorrupted information. In this sense, freedom of access to information is an essential corollary to freedom of expression in the modern cyber context. 
The article proceeds in three stages. The first section highlights and explores the issue of cyber coercion, reviewing some of the limitations of the key literature and setting the theoretical parameters for the discussion to follow. The second section explores how coercive cyber-attacks might affect freedom of expression. The third section reviews the large volume of cyber-attacks conducted against Ukraine's digital networks and assesses the extent to which they can be said to have had a direct or indirect influence in this area. The conclusion highlights the implications of that empirical assessment for the cybersecurity literature.

\section{Shaping adversary behaviour through cyber operations}

When the term 'cyber war' entered the popular discourse it was focused on efforts by states to disrupt and destroy the information systems of a military adversary (Arquilla \& Ronfeld, 1993, p. 30). The term cyber security naturally followed as a way of thinking about measures taken to enhance the safety and security, reliability, and integrity of computer systems in the face of malicious interference. If computers could be safeguarded from hostile actions, this would not only enhance military effectiveness, but protect the internet as a platform for communication, transparency, and accountability.

In recent years, the trend has been in the opposite direction. States have used the internet to spy on their populations, to interfere in the affairs of other states, for surveillance, espionage, and to sow political discord and resentment. Cyberattacks - the sending of malicious code from one computer to another with the intent of causing harm - have been viewed as a technological form of activity based around a platform of cables, servers, processors, screens and peripheral devices. This has belied the social and psychological aim and effects of the attacks, their cultural drivers, and their connections to historical and political disputes.

One of the most notable contributions to debates about the political effects of cyber-attacks has been the emergence of a distinct literature on cyber coercion. As Cold War theorist Thomas Schelling argued, military force is not used solely to achieve effects on the battlefield, it can be the basis of a threat that can coerce an adversary to change their behaviour (Schelling, 1960; 2008, pp. 69-86). Cyber-attacks are never violent in themselves. However, they can be used to force an adversary to do something that they would not otherwise have done (coercion), to do something against their interests (compellence), or to refrain from taking a course of action (dissuasion). Cyber coercion, compellence and 
dissuasion have become subsets of cyber deterrence theory, itself a central feature of recent cybersecurity literature (Jasper, 2017; Buchanan, 2014).

Cyber coercion is predicated on several core assumptions. First, a cyber-attack has wider political effects than just the degradation of computer networks. In this instance, the effect is to induce an adversary to change their behaviour by making threats to deny, degrade, or disrupt networks or affect the availability or integrity of the data stored on them. This is a staged process, involving a clearly communicated threat that is linked to a cost-benefit calculus. The coercive threat must be credible - the threat maker must be capable and willing to carry out the threat - and the target of the threat must be reassured that changing their behaviour will lead to a different outcome, including ensuring that the coercer will not mete out the intended punishment (Borghard \& Lonergan, 2017).

Cyber coercion is difficult to achieve in cyberspace. Many cyber operations are conducted with the attacker not claiming direct responsibility. This removes the ability to communicate a threat and to provide reassurance. It is difficult, moreover, to convince an adversary of the credibility of a cyber capability without revealing methods or proprietary technology. Cyber operations are necessarily covert and associated technologies are not counted in the open in the same way that conventional military assets are. If a party reveals what they are about to do, then cyber vulnerabilities can be patched and mitigated. While entry points will likely remain, threatening cyber-attacks may thus negate their utility and erode the effectiveness of the attempted coercion (Neuman \& Poznansky, 2016).

Given these problems with the coercion framework, how should we categorise the increasing volume of cyber-attacks which seem designed to influence a state's actions but which do not fit the conventional parameters of coercion? One conception which has helped to move the debate forward is that of cyber intimidation. This is similar to cyber coercion in that it involves the use of offensive cyber capabilities within an existing political dispute and/or armed conflict between two or more parties but involves a blunter political aim and rationale. The aim of such a strategy is to influence a public audience and sometimes the leader of a state and its policymakers, to undermine the legitimacy of a government, to create the impression that the government is unable to defend the population, and/or to shift political support. Borghard and Lonergan (2017) argue that cyber intimidation can be a viable strategy, but dismiss it as more of a nuisance, which does not achieve the effect of changing adversary behaviour. However, in some circumstances, cyber intimidation may have more pronounced effects. This depends on the target of a campaign of 
cyber intimidation. If critical infrastructure is affected, for example, the level of intimidation may be magnified. It may also depend on the recipient of the intimidation's own level of capability in cyberspace and in the conventional military space. If the effect is to convince the adversary that they have no reliable means to defend themselves, the level of intimidation will likely be higher. If the effect of the intimidation is to increase fear and anxiety in a target population, then the intimidation may be more successful. Leaders make decisions on the basis of public support, or a lack of it, but also in response to anger, anxiety, and or fear (Gomez \& Villar, 2018). This would appear to be one of the main ways in which coercion, at least as traditionally formulated, may be underdeveloped and in need of reformulation. Cyber intimidation's departure point from cyber coercion is that it relies on manipulating the feelings or emotions of a target, and is less of a rational process designed to result in a specific payoff.

If coercion does not capture the existing offensive use of cyber capabilities precisely enough, the concept of 'cyber swaggering' may also be a better fit. Swaggering moves beyond the assumption that coercion is a rationale strategy resulting in specific payoffs and suggests there is a difference between intent to coerce and the results of coercion-i.e., a state can try and use cyber to coerce an opponent, but that does not mean that the attempt will be successful and lead to a specific change of behaviour. An act of cyber swaggering may involve using a cyber capability in a limited way to signal intent and capability while not necessarily expecting specific changes in behaviour. This involves the influence of an ongoing process of bargaining between two or more adversaries in protracted political disputes, such as those in Ukraine. The act of swaggering can resolve uncertainties around the capabilities of the threat maker and may have a cumulative effect over time. In this sense, the intent of cyber swaggering is not necessarily to achieve a direct result, but to increase pressure and influence in a long running confrontation between two strategic adversaries (Valeriano, Jensen, \& Maness, 2018).

Cyber disruption is another option for states to pursue in the absence of clear benefits being derived from campaigns or acts of coercion. In this scenario, targeted cyber-attacks are conducted against government websites, and the targeting of financial systems, for example. These are usually low-cost, low-risk efforts to harass a target and to attempt to influence their calculus (Valeriano, Jensen, \& Maness, 2018), although the risk to the attacker may increase as responses to such efforts become more coordinated. The effect of such disruptions may be to signal intent on the part of the attacker, to signal the ability to inflict costs on an ongoing basis, to induce the target to question their own security and level of vulnerability, and to alter its decision making. These 
are further examples of measures taken to intimidate and harass a target to try and influence behaviour, but which stop short of securing direct and quantifiable concessions on the part of the victim of the campaign.

\section{Freedom of expression-hacking democracy and virtual occupations}

Despite the revised formulations of the political aim and utility of cyber-attacks covered in the previous section, few attempts have made to link cyber coercion and its associated concepts to broader political effects or to question how such attacks may affect the broader set of political freedoms enshrined in advanced democracies. I argue here that freedom of expression is notably absent from these modern conceptions of the political effects of offensive cyber campaigns. In this sense, a cyber-attack may induce a specific change in a decision, but it is more likely to lead to broader and less quantifiable outcomes. This might be to increase fear and anxiety, conditions under which speaking freely is constrained.

Freedom of expression is defined in the Universal Declaration of Human Rights as "the right of every individual to hold opinions without interference and to seek, receive and impart information and ideas through any media and regardless of frontiers" (UN, 1948). A key facet of this definition in the context of this article is the notion of being free from interference. If there are barriers to access to information, or that information is intentionally manipulated or corrupted, then this would appear to fall under the purview of the declaration. In the contemporary arena, and in many jurisdictions, this right has been limited by a variety of factors, including censorship, legislation which restricts freedom of the press and other media, including internet censorship, and the physical, mental, and online harassment of those reporting the news, including traditional journalistic outlets, but also bloggers and other online commentators. The right to freedom of expression has been argued to cover a variety of activities that citizens would ordinarily engage in, including freedom to express religious viewpoints free of intimidation and harassment, freedom to take part in protests, and freedom to exercise political rights, including, at least according to some legal analyses and interpretations, and subject to jurisdiction, the right to vote (Derfner \& Hebert, 2016). ${ }^{1}$

1 The right to vote has certainly been a controversial part of the conceptions of freedom of expression and is not automatically assumed to be part of a person's right to express themselves, but there are some scholars who take the view that it is part of the freedom and a part of a broader right of freedom of speech. 
Cyber-attacks have often been conceived in a Clausewitzian sense by security studies scholars, as a means of affecting material capabilities. But the subtler effects on the communications and information environment have sometimes been subsumed in the debate. Cyber warfare by this conception is information warfare and is intended to induce and create effects in the information domain, to alter perceptions, access to information, to create and sow division and discord, and to erode public support for a political actor or narrative through cyber-attacks. These activities have direct bearings on freedom of expression. This way of thinking about cyber warfare has been more prominent in China and Russia and has formed the basis of a divergence between the West and the East in conceiving of cyber war. In the same way that the West and Russia had different perceptions of detente, the great powers in the 21 st century have different perceptions of the utility of cyber (Giles \& Hagestad, 2013).

Freedom of expression has emerged as both a guarantee states provide to their citizens and as a legal framework enshrined in international treaties. In an age of transnational security threats and efforts across border to influence political dynamics, freedom of expression has increasingly been affected by foreign governments or by non-state actors residing in other states. In this way, freedom of expression is a legal guarantee given by a particular state as well as a political right accorded to citizens universally and regardless of nationality. The globalisation of internet coverage has regularly received attention in policy and academic debates, including relating to disputes about which countries' laws and values are to govern internet users' online behaviour, including their free expression rights. Notable among these analyses is the idea that cyberspace challenges the law's reliance on traditional borders and requires recognising the global information domain as a unique place (Johnson \& Post, 1997).

A third issue is the psychological impact of cyber-attacks and harassment online. While a cyber-attack designed to coerce may not legally breach freedom of expression, it may do so psychologically and socially. A reporter, government official or citizen may feel that their personal integrity and safety has been violated by a cyber-attack, may fear retribution against their reporting by the state or non-state actor conducting the attacks, and may be less likely to report on nefarious activities because their electronic devices have been breached, especially if those devices contain personal and identifying information that could create a subsequent threat to their safety. Sarah Cook takes up this line of reasoning in reference to Chinese efforts to intimidate journalists, arguing that "[p]sychological elements add another dimension, as fears over physical safety, access to the country or family privacy can make reporters think twice about what they write" (Cook, 2013). This is as true of online safety and commentary 
as it is of traditional reporting. In this scenario, attribution of a specific attack need not take place for the intimidation effect to be achieved.

Cyber-attacks have regularly been used by states across border to control and influence news reporting and verbal statements on political issues. This constitutes an act of interference. One example is the use of cyber-attacks by Chinese hackers to respond to reporting in the Philippines and other countries regarding the international tribunal ruling concerning the South and East China Seas (Piiparinen, 2016). At face value, this seems a clear attempt to harass and intimidate with the intention of shutting down critical reporting concerning China's role in the disputes. This is part of a form of collective punishment aimed to impede the work of news organisations, discourage the dissemination of critical reporting, and are activities that, through cyberspace, take place beyond China's border, affecting human rights directly (Cook, 2013).

Perhaps the most prominent example of a cyber-attack impacting freedom of expression was the Sony Hack in 2014. Cyber-attacks, allegedly by North Korean hackers, against SONY Pictures US, a response to the release of the film The Interview, which depicted the assassination of the North Korean leader Kim Jong Un, provoked a widespread debate on this issue. President Obama himself referred to the subsequent cancellation of the release of the film as a serious blow to freedom of expression, saying

We cannot have a society in which some dictators someplace can start imposing censorship here in the United States because if somebody is able to intimidate us out of releasing a satirical movie, imagine what they start doing once they see a documentary that they don't like or news reports that they don't like (Perez, 2014).

In this case, cyber-attacks were part of a broader pattern of intimidation on the part of the North Korean government, which included direct threats to cinemagoers. This was an example of a cyber operation being used alongside physical threats to impose costs for the release of the film.

As well as trying to intimidate, interfere with, and control media and political narratives through cyber-attacks, there have been numerous attempts by states to influence foreign elections, including though cyber espionage, and the exfiltration and subsequent leaking of information by malicious cyber-attackers. The most notable recent example is Russian interference in the US election that involved infiltrating DNC servers, a spear-phishing attacks against John Podesta, the DNC chair, and efforts to disseminate stolen information through WikiLeaks. The extent to which these acts affected freedom of expression is a complex question 
that strays into unresolved legal determinations and debates. Election meddling can reach the threshold of continuing coercion, if it would "deprive another State of its freedom of choice, that is, to force that State to act in an involuntary manner or involuntarily refrain from acting in a particular way" (Schmitt, 2012). If a state is being coerced, it is not free to express itself, especially if the coercion leads to actions taken to restrict information. While lower threshold activities like propaganda are excluded from this classification (Schmitt, 2018), trolling and subversion constitute a form of interference that had a variety of effects in the case of the US election. These include (a) depriving the US electorate of its freedom of choice because it was not possible for the US electorate to fairly evaluate the information it was being provided; (b) due to them not being aware of the manipulation, their decision making and judgment being distorted and weakened; and (c) that the unlawful penetration and exfiltration of data deprived the electorate of their freedom of choice (Schmitt, 2018).

If disinformation and misinformation is disseminated to the extent that it begins to corrupt public debate, and adversely influence the 'digital public square' this can constitute a virtual occupation or virtual infiltration by a foreign power, and arguably, a breach of a country's freedom of expression and those of groups or individuals within it. The example of the Arab Spring is worth noting here. In that case, protesters used social media to plan, organise and mobilise protest against the government in Egypt. This enabled the physical occupation of Tahrir Square in the Egyptian capital. Efforts to create an online movement that circumvented national media restrictions were successful but were fought against by the authoritarian Arab Spring governments, who put out false counternarratives about the protesters, and used online tools to bully, intimidate, and locate key organisers for arrest and arbitrary detention. The lessons derived by Russia and China from these events was that virtual occupations of the digital space could prove effective at stifling and hampering political narratives. Since the Arab Spring, various governmental and non-governmental actors have sought to weaponise the "attention economy" - which is defined as the monetisation and marketing of online users' time and attention, and to shift public opinion a behaviour through measure including disinformation, hate speech and harassment (Human Rights First, 2018). This constitutes a limit to freedom of expression. According to the influential thinker John Rawls (Petra et al., 2019), the concept of deliberative democracy presupposes that information is exchanged according to fair procedures and a discussion based on reason and not self-interest or power. The right of freedom of expression illustrates the dependency between free information and the right to participation in democratic activity. 


\section{Cyber-attacks and freedom of expression in Ukraine}

Cyber-attacks against Ukraine follow a pattern in recent cyber activity that provide context for the discussion and argument in this article. Russia-based hackers have often targeted countries in Russia's near abroad before, during, and in the aftermath of political disputes and military conflicts. The most notable examples are the cyber-attacks against Estonia in 2007, and the cyber operations against Georgia in the context of the Russia-Georgia war in 2008. The case of Estonia had a strong informational element and was designed to influence political narratives and media coverage of the dispute. As Samuli Haataja (2017) argues, this may have been a case of "informational violence" conducted against the Estonian state. The networks of Estonian media organisations were infiltrated and Russian hackers mounted an infiltration and occupation of Estonia's information space.

When conflict began between Russia and Ukraine in 2014 and the annexation of the Crimean Peninsula occurred, it was unsurprising that Russia accelerated its use of cyber operations against Ukrainian digital networks. This activity might have used new technologies but was part of a continuous stream of activity based on traditional Soviet approaches, including destabilisation, subversion, and active measures doctrine (Giles, 2016). They were also influenced by past experience of the Arab Spring uprisings, in which informational elements were used effectively, including denial of service (DDOS) attacks and Twitter-bots, to defuse and discredit protest movements (Giles, 2016).

Russia's established modus operandi is based on attrition - gradually wearing adversaries down through a combination of hybrid warfare tactics and the construction of an ascendant information narrative. Cyber operations are meant to supplement military ones not replace them, and to add to the sense among adversaries that Russia has already infiltrated information systems without deploying military force. The other facet of this approach is to create uncertainty about the likelihood of further attacks, to distract and sow anxiety and create an ominous shadow of the future. The creation of these social and psychological conditions aids Russia's overall strategic objectives, to protect its interests in its near abroad, and to minimise western influence and interference. These aims are achieved by technical tools, such as automated processes, AI-based algorithms, and bots, but also by a sustained investment in human resources, including trained foreign-language speakers and the recruitment of journalists to participate in information warfare campaigns with the aim of affecting mass consciousness through mass manipulation of information (Giles, 2016, p. 29). 
While the volume and scope of Russia cyber operations in Ukraine are too large to cover in one article, there are some overall observations to be made about the impact of cyber operations within the conflict. Attacks have not created largescale destruction, allowing Russia to stay below the threshold of what would be considered an armed attack on Ukraine. The impact of cyber-attacks on war-fighting in Ukraine and the correlation between violence and cyber-attacks in Ukraine is also weak, according to the latest research (Kostyuk \& Zhukov, 2019). Russia has denied involvement in major cyber-attacks perpetrated against Ukraine's digital networks, and pointed to the involvement of Ukrainian hacker groups, and patriot hackers, as a prominent feature of the conflict. However, many of the attacks have clearly benefited Russia and supported its overall objectives and the attacks have served subtler political and ideological effects, which are significant and damaging.

The most significant cyber campaigns and activities appear to reveal both indirect and direct effects and influences on the freedom of expression of the Ukrainian people. First, there has been a tendency during the Ukraine conflict to use cyber-attacks to attempt to intimidate the opposition. In various instances, the hacker group CyberBerku hacked and subsequently leaked communications from government officials, including from the US, EU and Ukraine itself, and disclosed the identities of Ukraine military personnel who were loyal to Kyiv (Kostyuk \& Zhukov, 2019). The main targets of this side of the conflict include media, government officials, and private citizens, suggesting the importance of the aim of creating fear and insecurity to control action and narratives. Meanwhile, the Myrotvorets' website published the personal details of people involved in the dispute, allegedly leading to several assassinations (Kostyuk \& Zhukov, 2019). Apart from constituting a grave human rights abuse, this is a clear abrogation of right to privacy, which has been linked to freedom of expression (Wilton, 2017, p. 18). In a similar vein, attempts were made to limit the freedom of expression of protesters during the Euromaidan street demonstration, including through the use of online attacks by hackers linked to Russia targeted at opposition servers, smartphones, websites, and internet accounts. These attacks coincided with physical attacks against protesters, including lethal shootings (Geers, 2015, p. 11). Again, this suggests a strong correlation at least between the desire to penetrate digital networks and the desire to intimidate people who were exercising their political rights of expression through protest.

In the elections space, evidence has arisen over attempts to effect and subsume electoral processes through cyber-attacks. National election campaigns have coincided with a spike in cyber-attacks, and the Ukraine's Central Electoral Committee website was targeted by DDOS attacks and malware attacks in May 
2014. These had several effects bearing on freedom of expression as outlined in the previous section, including impeding information exchange, underlining the credibility of the election, presenting false election results via the official election website, which were then reported on by Russian television (Geers, 2015). The outcome of the election was not threatened by these attempts at subversion, and various anti-fraud measures were in place, including the Ukrainian Security Service removing malware from election machines prior to the vote (Weedon, 2015). However, the ability of hackers to affect electoral processes and to influence public opinion through these types of measures is a serious problem that should not be underestimated. As Koval (2015) argues, "Any serious disruption during an election would generate immediate suspicion about its legitimacy and spark a desire for a new election." It may also be the case that election interference in Ukraine was a test case for Russian hackers, who realised this political effect, and put it to use in the US elections the following year.

Elements of a 'virtual occupation' are also in force in Ukraine. This point should be made in the context of Russian ownership of much of the digital networks that supply Ukrainian citizens their internet services. Nevertheless, the effects of manipulation of information throughout the period of the Ukraine conflict are a significant example of this type of tactic. This line of reasoning is taken up by Keir Giles who states that one of the aims of Russia in the conflict has been to "isolate the domestic audience from non-approved information so that Russian state actions are permissible" (Giles, 2016, p. 38). These tactics were not just applied in Russia, but in Crimea, where Russia achieved total domination of the information space, and to a lesser extent in other parts of Ukraine, where the Russian state disseminated "polluted information" to influence narratives (Giles, 2016, p. 38). This would appear to be in line again with the theoretical parameters outlined in the previous section, where restricting access to information constitutes an abrogation of freedom of expression. There have also been reported uses of cybercrime malware to promote pro-Russia video clips on social media (Kogan, 2015). The cumulative layering of these effects over continued periods of time may have shifted public opinion in important but empirically difficult to determine ways. Other examples of attempted occupation of the information space include hacking into election billboards with adverts proclaiming Ukrainian politicians to be neo-Nazis and threatening the country with chaos and civil war, a tactic which may well have increased the fear among the Ukrainian population and influenced their political viewpoints (Lange-Ionatamishvili \& Svetoka, 2015, p. 106).

Perhaps the most notable cyber-attack affecting Ukraine was the 'NotPetya' malware event affecting Ukrainian and international networks in 2017. The 
attack gained widespread international coverage and has been attributed by Western security agencies and by Ukraine to Russian military intelligence (Buchanan \& Rid, 2018). The malware targeted Ukraine's tax reporting software but spread internationally causing billions of dollars of damages. It was also an embarrassing incident for the US National Security Agency (NSA) as the malware utilised the Eternal Blue exploit, which the NSA had stockpiled, and which was subsequently hacked, released, and weaponised. Analyses of the attacks are still limited, but some have suggested that the hack was not just intended to cause widespread damage, but to clean up systems by wiping their data, thus concealing previous intrusions and attempts at cyber espionage (Greenberg, 2018). This could be further evidence of virtual occupation and infiltration that affects the free flow and integrity of data. Another theory is that the malware was intended to send a political message to companies not to invest in the Ukrainian economy as part of a broader effort to intimidate the Ukrainian government, leading to the question: does decision to invest in a country constitute freedom of expression? Taken in isolation, the 'NotPetya' attack may not constitute an impact on freedom of expression, but analysed as part of a growing pattern of cyber activity, the use of Ukraine as a test bed for cyber-attacks, and the evident involvement of the Russian state, the tactic may constitute a broader pattern of intimidation designed to shape the political landscape.

Finally, the notable attack on Ukraine's electricity grid in 2015 is worth noting here. The attack, allegedly by Russian hackers, led to 230,000 Ukrainian citizens being without power, and shut down dozens of power substations. Speculation about the motivations for the attack is rife. Some have linked the attacks as part of a retaliation for pro-Ukraine hackers taking down the power grid in Crimea, and other suggestions have been made to the effect that this was aimed to shape commercial decisions in Ukraine over energy rights (Zetter, 2016). An intimidatory political and economic environment has clearly been created by these widespread cyber operations, but more specifically, attacks against energy supplies clearly contribute to an intimidatory environment in which politicians in Ukraine may anticipate potential costs for certain decisions and courses of action. 


\section{Conclusion}

In March 2019, Ukraine held another election which saw further cyber interference. While this article does not recount all the implications of this meddling, the activities appear to amount to a continuation of the central themes of this article. Malicious activities include attacks against electoral servers, the hacking and trading of the personal information of Ukrainian personnel on the dark web, and targeting hacks against civil servants and employees with responsibility for keeping the electoral commission's equipment running (Polityuk, 2019).

In this ongoing context, this article has attempted to begin to fill what I see as a significant gap in the cybersecurity literature by looking at the effect of cyber-attacks on freedom of expression. I make both a theoretical argument and an empirical one: cyber-attacks can cause an adverse effect on freedom of expression, particularly when they are targeted at electoral processes, designed to intimidate through social and psychological effects, and when they constitute a virtual intimidation and virtual occupation of the digital public square.

While we should continue to be wary about overstating the effect of cyber operations, evidence from Ukraine does appear to indicate that the role of cyberattacks was not only to create military advantages (cyber war in the kinetic sense) but to create information effects, including affecting freedom of information, adverse effects on electoral processes, occupation of the information domain that citizens rely on to make informed decisions, and the creation of a wider environment of fear and anxiety that would favour Russian objectives. My analysis supports the widely held scepticism about the physical damage that can and is created by cyber operations and helps to nudge the field further towards the subtler informational, socio-psychological, and political effects of cyber warfare. The article supports the premise that cyber coercion is difficult to achieve, and that cyber-attacks are designed less to achieve specific payoffs, but to create an atmosphere of intimidation in which the interests of an adversary are protected and enhanced. The precision and clarity that Schelling brought to coercion debates in the Cold War period appears to be out of reach within the fog of protracted cyber conflicts.

The limitations of this study constitute areas for research. This includes a tighter quantitative analysis of freedom of expression effects over longer time periods. The analysis in this article is necessarily exploratory and deductive and stands on the shoulders of the excellent previous work of Ukraine scholars and 
scholars working on cyber coercion and the political effects of cyber operations. I recognise that more quantitative work needs to be done to verify my assertions that freedom of expression is affected in real and substantive ways. The lack of verifiable data on cyber operation continues to be a major challenge for the emerging cybersecurity discipline. I also note again that our definition of freedom of expression is not a rigid one and incorporates elements of political freedom that exist transnationally and may not be specifically codified in domestic or international law. Another opportunity for further research is to look at the sustained and short-term cognitive effects of cyber operations and the way they influence political and societal trends and activities - this work is beginning to be done at a serious level (see Gomez \& Villar, 2018; Libicki, 2018) but remains a deep well for future scholarly enquiry.

Dr. Joe Burton holds a doctorate in international relations and a master of international studies degree from the University of Otago and an undergraduate degree in international relations from the University of Wales, Aberystwyth. He is a recipient of the US Department of State SUSI Fellowship, the Taiwan Fellowship, and has been a visiting researcher at the NATO Cooperative Cyber Defence Centre of Excellence (CCD COE), Tallinn, Estonia. Joe is the author of NATO's Durability in a Post-Cold War World (SUNY Press, 2018) and his work on NATO and cybersecurity has been published in Asian Security, Defence Studies, Political Science, and with a variety of other leading academic publishers.

\section{References}

Aquila, J. \& Ronfeldt, D. (1993), 'Cyberwar is coming!' RAND Corporation. Retrieved from https://www.rand.org/pubs/reprints/RP223.html [accessed 6 Oct 2019]

Bárd, P.; Uszkiewicz, E.; Alemanno, A.; Bayer, J.; Szakács, J. \& Bitiukova, N. (2019), 'Disinformation and propaganda Impact on the functioning of the rule of law in the EU and its Member States.' Retrieved from http://www.europarl.europa. eu/thinktank/en/document.html?reference=IPOL_STU(2019)608864 [accessed 12 May 2019]

Borghard, E. D. \& Lonergan, S. W. (2017), 'The logic of coercion in cyberspace,' Security Studies, vol. 26, no. 3, pp. 452-481. https://doi.org/10.1080/09636412.2 017.1306396

Buchanan, B. (2014), 'Cyber deterrence isn't MAD; it's mosaic,' International Engagement on Cyber IV: Post-Snowden Cyberspace, Georgetown Journal of International Affairs, pp. 130-140. 
Cook, S. (2013), 'Congressional-executive commission on China roundtable China's treatment of foreign journalists,' Freedom House. Retrieved from https:// freedomhouse.org/article/china-treatment-foreign-journalists [accessed 12 May 2019]

Derfner, A. \& Hebert, J. G. (2016), 'Voting is speech,' Yale Law and Policy Review, vol. 34 , no. 2 , p. 471.

Geers, K., ed. (2015), Cyber War in Perspective: Russian Aggression against Ukraine, Tallinn: NATO CCD COE Publications.

Giles, K. (2015), 'Russia and its neighbours: old attitudes, new capabilities,' in K. Giles \& K. Geers (eds.) Cyber War in Perspective: Russian Aggression against Ukraine, Tallinn: NATO CCD COE Publications, pp. 19-28.

Giles, K. (2016), Russia's 'New'Tools for Confronting the West: Continuity and Innovation in Moscow's Exercise of Power, Chatham House Research Paper. Retrieved from https:/www.chathamhouse.org/sites/default/files/publications/2016-03-russianew-tools-giles.pdf [accessed 12 May 2019]

Giles, K. \& Hagestad, W. (2013), 'Divided by a common language: Cyber definitions in Chinese, Russian and English, 5th International Conference on Cyber Conflict (CYCON 2013), pp. 117.

Gomez, M. \& Villar, E. (2018), 'Fear, uncertainty, and dread: cognitive heuristics and cyber threats,' Politics and Governance, vol. 6, no. 2, pp. 61-72. https://doi.org/10.17645/pag.v6i2.1279

Greenberg, A. (2018), 'The untold story of NotPetya, the most devastating cyberattack,' Wired. Retrieved from https://www.wired.com/story/notpetya-cyberattackukraine-russia-code-crashed-the-world/ [accessed 12 May 2019]

Hodgson, Q. (2018), 'Understanding and countering cyber coercion' in T. Minárik, R. Jakschis \& L. Lindström (eds.) 10th International Conference on Cyber Conflict CyCon X: Maximising Effects, Tallinn: NATO CCD COE Publications, pp. 73-88. https://doi.org/10.23919/CYCON.2018.8405011

Human Rights First (2108), 'Fake news, free speech, and foreign influence: the smart way the United States can combat disinformation.' Retrieved from https://www. humanrightsfirst.org/sites/default/files/Disinformation-Brief-March-2018.pdf [accessed 12 May 2019]

Jasper, S. (2017), Strategic Cyber Deterrence: The Active Cyber Defense Option, Lanham, ML: Rowman \& Littlefield.

Jensen, B.; Valeriano, B. \& Maness, R. (2018), Cyber Strategy: The Evolving Character of Power and Coercion, Oxford: Oxford University Press.

https://doi.org/10.1093/oso/9780190618094.001.0001

Johnson, D. R. \& Post, D. G. (1996), 'Law and borders - the rise of law in cyberspace,' Stanford Law Review, vol. 48, no. 5, pp. 1367-1402.

https://doi.org/10.2307/1229390 
Kogan, R. (2015), 'Bedep trojan malware spread by the Angler exploit kit gets political,' Trustwave. Retrieved from https://www.trustwave.com/Resources/SpiderLabsBlog/Bedep-trojan-malware-spread-by-the-Angler-exploit-kit-gets-political/ [accessed 12 May 2019]

Kostyuk, N. \& Zhukov, Y. (2019), 'Invisible digital front: can cyber attacks shape battlefield events?' Journal of Conflict Resolution, vol. 63, no. 2, pp. 317-347. https://doi.org/10.1177/0022002717737138

Koval, N. (2015), 'Revolution hacking,' in K. Geers (ed.) Cyber War in Perspective: Russian Aggression against Ukraine, Tallinn: NATO CCD COE Publications, pp. 55-58.

Libicki, M. C. (2018), 'Drawing inferences from cyber espionage,' in T. Minárik, R. Jakschis \& L. Lindström (eds.) 10th International Conference on Cyber Conflict CyCon X: Maximising Effects, Tallinn: NATO CCD COE Publications, pp. 109-122. https://doi.org/10.23919/CYCON.2018.8405013

Neuman, C. \& Poznansky, M. (2016), 'Swaggering in cyberspace: busting the conventional wisdom on cyber coercion,' War on the Rocks, 28 June. Retrieved from https://warontherocks.com/2016/06/swaggering-in-cyberspace-busting-theconventional-wisdom-on-cyber-coercion/ [accessed 12 May 2019].

Past, L. (2015), 'Missing in action: rhetoric on cyber warfare,' in K. Geers (ed.) Cyber War in Perspective: Russian Aggression against Ukraine, Tallinn: NATO CCD COE Publications, pp. 95-102.

Piiparinen, A. (2016), 'China's secret weapon in the South China Sea: cyber attacks,' The Diplomat, 22 July. Retrieved from https:/thediplomat.com/2016/07/chinassecret-weapon-in-the-south-china-sea-cyber-attacks/ [accessed 12 May 2019]

Rid, T. \& Buchanan, B. (2018), 'Hacking democracy,' The SAIS Review of International Affairs, vol. 38, no. 1, pp. 3-16. https://doi.org/10.1353/sais.2018.0001

Schelling, T. C. (1960), The Strategy of Conflict, Cambridge, MA: Harvard University Press.

Schelling, T. C. (2008), Arms and Influence, New Haven, CT: Yale University Press.

Schmitt, M. N. (2018), 'Virtual disenfranchisement: cyber election meddling in the grey zones of international law,' Chicago Journal of International Law, vol. 19, no. 1 , pp. 8-16.

Universal Declaration of Human Rights (1948), United Nations General Assembly, New York. Retrieved from https:/www.un.org/en/universal-declaration-human-rights/ [accessed 12 May 2019]

Weedon, J. (2015), 'Beyond 'cyber war': Russia’s use of strategic cyber espionage and information operations in Ukraine,' in K. Geers (ed.) Cyber War in Perspective: Russian Aggression against Ukraine, Tallinn: NATO CCD COE Publications, pp. 67-78. 
Wilton, C. (2017), 'Sony, cyber security, and free speech: preserving the First Amendment in the modern world,' Pace Intellectual Property, Sports \& Entertainment Law Forum, vol. 7, no. 1.

Zetter, K. (2016), 'Inside the cunning, unprecedented hack of Ukraine's power grid,' Wired, 3 March. Retrieved from https://www.wired.com/2016/03/inside-cunningunprecedented-hack-ukraines-power-grid/ [accessed 12 May 2019] 